\title{
A relação entre a felicidade e o desejo por hospitalidade mediada pela autoimagem do turista e a imagem do seu destino
}

\section{The Relationship Between Happiness And The Desire For Hospitality Mediated By Tourism Self-Image And The Image Of Its Destiny}

\section{A relacion entre a felicidad y desejo por hospitalidad mediada pela autoimagem de turista y a imagem do seu destino}

\author{
Leonardo Aureliano-Silva ${ }^{1}$ \\ Paulo Sergio Gonçalves de Oliveira ${ }^{2}$ \\ Carlos Alberto Alves ${ }^{3}$
}

\begin{abstract}
Resumo: Essa pesquisa justifica-se pela necessidade de ampliar a teoria sobre comportamento do consumidor no turismo e a importância do aprimoramento de práticas comerciais. O principal objetivo deste estudo é analisar a relação entre a busca da felicidade na experiência turística e o desejo por hospitalidade local, mediada pela congruência entre a autoimagem do turista e a imagem do destino. Por meio de uma survey obtevese 221 questionários respondidos. Para análise dos dados, utilizou-se abordagem quantitativa com o uso da técnica de regressão linear múltipla, e os resultados indicaram relação significativa e positiva entre a busca da felicidade na experiência turística e o desejo por hospitalidade local, mediada pela congruência da autoimagem do turista (como ele se vê) e imagem do destino turístico. A originalidade deste estudo está em identificar a autoimagem do turista e destino turístico como fatores mediadores da percepção de hospitalidade local.
\end{abstract}

Palavras-chave: Felicidade. Hospitalidade. Turismo. Autoimagem. Congruência.

Abstract: This research is justified by the need to broaden the theory about consumer behavior in tourism and the importance of improving commercial practices. The main objective of this study is to analyze the relationship between the search for happiness in the tourist experience and the desire for local hospitality, mediated by the congruence between the tourist's self-image and the destination image. A survey yielded 221 completed

\footnotetext{
${ }^{1}$ Universidade Anhembi Morumbi (UAM) e Escola Superior de Propaganda e Marketing (ESPM), São Paulo, SP, Brasil. Elaboração do Referencial Teórico, Coleta dos Dados, Análise dos Dados e Relatório de Pesquisa.

2 Universidade Anhembi Morumbi (UAM), São Paulo, SP, Brasil. Elaboração do Referencial Teórico, Coleta dos Dados, Análise dos Dados e Relatório de Pesquisa.

${ }^{3}$ Universidade Anhembi Morumbi (UAM), São Paulo, SP, Brasil. Elaboração do Referencial Teórico, Coleta dos Dados, Análise dos Dados e Revisão Final.
} 
questionnaires. To analyze the data, a quantitative approach was used with the use of the multiple linear regression technique, and the results indicated a significant and positive relationship between the search for happiness in the tourist experience and the desire for local hospitality, mediated by the congruence of tourist self-image ( As it is seen) and image of the tourist destination. The originality of this study is to identify the selfimage of the tourist and tourist destination as factors mediating the perception of local hospitality.

Keywords: Happiness. Hospitality. Tourism. Self-Image. Congruence.

Resumen: Esta búsqueda justifica-se en la necesidad de ampliar una teoría sobre el comportamiento del consumidor en el turismo y un aumento en el desarrollo de los préstamos comerciales. $O$ principal objetivo este estudio es una relación entre una búsqueda de la felicidad en la experiencia turística y la búsqueda por la hospitalidad local, la meditación por la congruencia entre una autoimagen de la turista y una imagen del destino. Por medio de una encuesta obteve-se 221 cuestionarios respondidos. Para la evaluación de los datos, la utilización de la cuantitativa con el uso de la técnica de la regresión múltiple lineal, los resultados indicaron la relación significativa y positiva entre la búsqueda de la felicidad en la experiencia turística y el deseo por la hospitalidad local, mediada por la congruencia de la autoimagen del turista (como se ve) y la imagen del destino turístico. Una originalidad de este estudio es identificar una autoimagen de turista y de destino mediadores de la percepción de hospitalidad local.

Palabras clave: Felicidad. Hospitalidad. Turismo. Autoimagen. Congruencia.

\section{INTRODUÇÃO}

Neste estudo, aborda-se o conceito de felicidade, como emoções positivas relacionadas à experiência no consumo turístico e sua relação com a percepção de hospitalidade local.

De acordo com Espinoza e Nique (2003) a felicidade é um sentimento de importância para os indivíduos e está relacionado a emoções positivas que influenciam a intenção comportamental. $\mathrm{O}$ argumento que se estabelece é que o consumo turístico, como experiência hedônica, leva o consumidor a ações positivas, influencia a forma como vê a si mesmo e como percebe os demais com o qual interage (Yampey, 1980).

O termo hospitalidade, que também será tratado neste artigo, possui diferentes definições e está relacionado, por exemplo, a provisão de alimentos e bebidas, manutenção de status e satisfação de necessidades psicológicas (King, 1995; Lynch, Molz,
Mcintosh, Lugosi, \& Lashley, 2011). Também encontra-se o termo hospitalidade no do campo management, cujos estudos referem-se à hospitalidade e atendimento das necessidades dos clientes em contextos de compra (Bareham, 2004), hospitalidade, comportamento e experiência de compra (Hemmington, 2007) e ainda, em outras dimensões da gestão (Nailon, 1982). Um ponto comum sobre o conceito de hospitalidade que se observa na literatura, refere-se a sua natureza de acolhimento ao outro (Bareham, 2004) no sentido de fazer com que este se sinta bem.

Dessa maneira, os conceitos de felicidade e hospitalidade, serão teorizados e testados em um modelo exploratório para identificar e analisar a sua relação.

Outro aspecto que será considerado neste estudo, refere-se na escolha do destino turístico pelo consumidor. Em seu processo de escolha do destino turístico, o consumidor leva em conta não apenas os custos 
envolvidos na aquisição do serviço, mas também, o quanto o local de destino está em harmonia com o sei perfil. A esse fenômeno é dado o nome de congruência (Hosany \& Martin, 2012) que consiste na harmonia entre a autoimagem do consumidor (como ele se vê), e a imagem do destino turístico de sua escolha (Ahn, Ekinci, \& Li, 2013).

Baseado na Emotional Contagion (Hatfield, Cacioppo, \& Rapson, 1994), acredita-se que a autoimagem do consumidor e a imagem do destino turístico, tem função mediadora da relação entre a busca pela felicidade na experiência turística e a percepção de hospitalidade local. Com essa pesquisa, objetiva-se compreender aspectos importantes na escolha do destino turístico, a influência da congruência entre a autoimagem do consumidor em suas escolhas turísticas, e como esses aspetos influenciam a percepção de hospitalidade do destino turístico.

Além de contribuir para a literatura sobre hospitalidade, turismo e marketing, este artigo apresenta contribuições substanciais que podem ser consideradas por gestores de operadoras de turismo no atendimento a clientes e campanhas de marketing aplicado ao turismo.

Após essa breve introdução é apresentada a revisão teórica sobre felicidade, enquanto conjunto de emoções positivas, hospitalidade sob a perspectiva do acolhimento ao turista, e autoimagem do turista (como ele se vê) e a imagem do destino turístico. Na sequência, apresenta-se o método utilizado para análise dos dados, a discussão geral dos resultados e por fim, as contribuições teóricas, substanciais e limita- ções da pesquisa.

\section{REVISÃO DA LITERATURA}

Neste item serão apresentados estudos sobre hospitalidade, felicidade, e autoimagem do consumidor que servirão de base para elaboração das hipóteses de estudo.

\subsection{Felicidade no turismo}

De acordo com Espinoza e Nique (2003) a felicidade é um sentimento de muita importância para os indivíduos e está relacionado a um conjunto de emoções positivas que influenciam a intenção comportamental destes. É uma visão um pouco diferente da Nietzche (2016) que apregoa a felicidade como algo que os seres humanos querem apenas desejá-la, mas não possuí-la, onde cada indivíduo aprende durante a rezar por inquietações. Essa visão é de certa forma aproveitada no campo do marketing, onde tem sido argumentado que o consumo é um meio para a busca da felicidade (DeLeire \& Kalil, 2010). Para Braudrillard (2008) existe um sistema ideológico criado pelo mercado que fortalece a relação entre consumo e felicidade. Essa visão aproveita o conceito de felicidade proposto por Kant, no qual tudo decorre conforme o seu desejo e a sua vontade, ou seja, o consumidor sente um instante de felicidade ao desejar e comprar algo.

Há um corpus teórico muito relatado na literatura de marketing cuja investigação abarcou o consumo sob a perspectiva hedônica (Ben-Ur, Mai, \& Yang, 2015; Hirschman \& Holbrook, 1982; Lacher, 1989; Neeley, Sam Min, \& Kennett-Hensel, 2010; Nicolao, 
2010), ou seja, o consumo que gera prazer e felicidade, por exemplo, o consumo de gastronomia de luxo (Hemzo \& Augusto, 2010), o consumo de música (Lacher, 1989), e o consumo turístico (Rubio Gil, 1996).

Nesse sentido, o argumento que se estabelece é que o consumo turístico, como experiência de felicidade, e por sua natureza hedônica, leva o consumidor a ações positivas, influencia a forma como vê a si mesmo e também como percebe os demais com o qual interage (Yampey, 1980), resultando em um julgamento mais positivo na interação social.

A importância desse aspecto reside no fato do turismo ser o motor de crescimento econômico, porém o fato da felicidade gerada por ele e a sua capacidade em contribuir com a boa saúde está apenas começando a ser documentada (Bojanowska \& Zalewska, 2016; Filep \& Bereded-Samuel, 2012a; Hofmann, Luhmann, Fisher, Vohs, \& Baumeister, 2014).

Por essa razão Filep e BareedSamuel (2012b) estudaram entre a comunidade de imigrantes Etíopes na Austrália, de que forma as experiências positivas no feriado, que envolve a visita a amigos ou parentes melhora a saúde mental, alivia os níveis de depressão e dessa forma melhora os níveis de felicidade das pessoas que viajam. Eles justificaram esse estudo pelo fato da indústria do turismo estar aumento o interesse em entender como as viagens afetam os níveis de felicidade dos indivíduos, gerando mais saúde.

Esse aspecto é tão importante que alguns países tais como o Butão, possuem uma política de turismo totalmente guiada pela doutrina de Produto Nacional de Felici- dade $(G H N)$, que aparentemente se sobrepõe as demais políticas, fazendo dessa forma com que esse país ganhe reputação no mapa mundial do turismo. A importância dessa política reside no fato de que em razão dela, houve um significativo investimento no desenvolvimento de aspectos socioeconômicos, conservação ambiental, promoção da cultura e boa governança (os quatro pilares da política), a importância disso reside no fato de que para que as pessoas que visitam os destino se sintam felizes é muito importante que as pessoas que residem lá, seja felizes e dessa forma possam transmitir esse sentimento para os seus visitantes, o qual está muito ligado a satisfação proporcionada pelo lugar (Coffey, Warren, \& Gottfried, 2015; Khamrang, 2013; Yang \& Srinivasan, 2016).

Esse aspecto é corroborado pelo estudo de Kaliterna-Lipovčan, Brasjša-Žganec e Poljanec-Borić (2014) que examinaram a qualidade dos destinos turísticos está ligada ao bem-estar subjetivo das pessoas que residem naqueles destinos, para chegar a essa conclusão eles estudaram dois conjuntos de dados: um que relacionava o bem-estar dos cidadãos da Croácia e o outro que relacionava a qualidade dos destinos turísticos no país, no qual puderam constatar por meio de uma análise de covariância que quanto maiores eram os graus de felicidade e satisfação dos cidadãos, maior era a qualidade do destino turístico (Kaliterna-Lipovčan et al., 2014).

Nawijn e Peeters (2010) por outro lado estudaram a felicidade do ponto de vista dos turistas, o que os fez perceber que o que afetava a felicidade desses turistas era a liberdade que eles percebiam em 
se deslocar no destino afetava diretamente os índices de felicidade, o que os fez concluir que se as políticas públicas restringirem essa liberdade irá afetar negativamente a felicidade do turista e possivelmente a probabilidade de que esse turista retorne a esse destino.

Essa percepção corrobora com o estudos de Loubser \& Steenekamp (2017) e (Spruk \& Kešeljević (2016) ao pesquisar a felicidade relacionada a democracia e a liberdade existentes nos países que estudaram e puderam constatar um correlação entre a felicidade e aos altos níveis de segurança proporcionados pelo fato de serem locais democráticos e por outro lado baixos níveis de satisfação quanto maior fossem as mudanças políticas e econômicas, o que nos dá ideia de quanto mais liberdade os turistas perceberam, maior será o grau de felicidade.

Nawijn(2010) observa ainda que a importância de se estudar esses aspectos se deve ao fato da Indústria de Turismo dar pouca atenção para o humor dos turistas durante as viagens e de como ele afeta a satisfação de vida dos seus clientes como um todo e também como esse aspecto se relaciona ao aumento das receitas dessas empresas.

Também é importante prestar atenção ao fato de existirem diferenças sutis entre a felicidade percebida entre homens e mulheres de acordo com as condições sociais e culturais, as quais variam também de acordo com o país de origem, a religião e ao fato de viverem ambientes rurais ou não, apesar de sutis se faz interessante que os operadores de turismo prestem atenção a esses aspectos também, objetivando prestar um serviço de melhor qualidade por meio de atitudes que agradem os viajantes (Meisenberg \& Woodley, 2015).

Porém essa alteração do humor e os índices de felicidade causadas no viajantes são aspectos temporários que devem ser enfatizados sempre, mas que existe em maior grau em pessoas que viajam do que aquelas que não viajam, o que pode ser explicado pelo fato de as memórias positivas remanescentes afetaram positivamente a vida das pessoas (Nawijn, 2011).

\subsubsection{Hospitalidade}

O termo hospitalidade é relatado na literatura de diferentes formas e abrange variadas situações, por exemplo, na provisão de alimentos e bebidas ao convidado, na manutenção de status nas relações sociais e na satisfação de necessidade psicológicas (King, 1995; Lynch et al., 2011). Também se pode encontrar o termo hospitalidade dentro do campo management, cujos estudos referem-se, por exemplo, à hospitalidade e atendimento das necessidades dos clientes e os fatores no comportamento de compra (Bareham, 2004), hospitalidade, comportamento e experiência de compra (Hemmington, 2007) e ainda, em outras dimensões da gestão (Nailon, 1982). Sob essa perspectiva, o ponto comum que se encontra nesses estudos, é a importância dada ao acolhimento do indivíduo a fim de atender suas necessidades fisiológicas, psicológicas e sociais (Bareham, 2004; Hemmington, 2007; Nailon, 1982), no sentido de fazer com que o consumidor se sinta bem emocionalmente em suas experiências de compra.

Para se atender a esses requisitos de atendimento as empresas da indústria do 
turismo estão passando por um verdadeiro desafio, durante as últimas décadas ocorreram mudanças profundas estão levadas a cabo bem como o desenvolvimento das nações, devidas principalmente aos avanços econômicos e tecnológicos (Chand, 2016).

Estas mudanças impuseram uma série de desafios no sistema educacional como um todo, incluindo o currículo das instituições de ensino, os materiais para o aprendizado etc. A indústria de turismo e hospitalidade assume um papel central nesse cenário, devido ao fato de as pessoas viajarem cada vez mais, o que as leva a novas percepções de hospitalidade e também devido ao fato de ser uma indústria intensiva em serviços, o que demanda mão de obra especializada e educada em grande número, o que gera um desafio adicional para os países (Chand, 2016).

As Instituições de Ensino na área de hospitalidade são consideradas um fator chave para o fornecimento de mão de obra qualificada para a indústria de hotelaria, contribuindo significantemente para o crescimento das operações nessa área (Alhelalat, 2015).

Porém Yap et al.(2015) apontam que é importante na indústria de hospitalidade o desenvolvimento dos alunos via educação tradicional o métodos contemporâneos, principalmente no que tange a aspectos gerenciais, , isso se deve ao fato dessa área estar baseada principalmente no contato com o cliente e a sua característica central do serviço ser prestado face-a-face, muitas vezes requerendo criatividade e competências gerenciais dos colaboradores.

A importância do Turismo para alguns países é vital, como é o caso de Taiwan por exemplo, principalmente devido ao fato de representar entrada de receita e geração de empregos na área de hospitalidade, fazendo com que esses países criem mecanismos de transporte e comunicações que favoreçam o aumento de turistas que visitam esses países, tanto para negócios quanto para lazer (Chen, 2015).

Essa importância se deve muito ao fato da hospitalidade ser o tecido central de muitas sociedades, porém possui um desafio a parte pois o termo possui muitos significados e interpretado de formas diferentes em diversos países, de acordo com a ideologia, tendo inclusive relação com Deus ou Deuses em alguns casos (Munasinghe, Hemmington, Schänzel, Poulston, \& Fernando, 2017).

Por essa razão muitos países estão sendo afetados, inclusive aqueles que eram considerados fechados e portanto conservadores, no passado, tais como a China, que está enfrentando um grande desafio atualmente, devido principalmente a sua rápida modernização, o que a levou a se focar recentemente em um gerenciamento da diversidade em seu currículo escolar no que se refere a hospitalidade, de forma a atender a essa nova demanda, principalmente no que se refere a entender a percepção dos estudantes (futuros gestores) em relação a importância da diversidade, de forma a gerar no cliente uma percepção de hospitalidade (Yap, Ineson, Tang, \& Fong, 2015).

O investimento no estudo da diversidade se deveu principalmente ao fato de a satisfação do cliente na indústria de hospitalidade ser muito ligada aos conceitos que envolvem aos sentimentos de bem-estar e prazer que são resultantes do que o cliente espera e deseja dos produtos e serviços. A 
satisfação do cliente também pode ser baseada nos resultados e também nos processos, mas sua importância reside no fato de que a sua percepção determina a qualidade que é atualmente entregue pelo estabelecimento e dessa forma é essencial para a sua sobrevivência corporativa, no geral os aspectos percebidos pelos clientes são: cortesia e eficiência dos funcionários, suprimentos e amenidades para os hospedes, cortesia e simpatia, condição geral do quarto, temperatura do quarto, restaurantes, qualidade dos serviços, qualidade e variedade das refeições (Gupta \& Sharma, 2016; Hornsby \& Scott-Halsell, 2015).

Nesse contexto Sangode (2016) analisa os parâmetros de satisfação, que são formados principalmente por aspectos tais como: dar atenção ao cliente, qualidade da comida servida, identificação das expectativas futuras dos clientes e auto nível de avaliação do cliente geram diferença na visão do cliente em relação ao hotel, causando uma visão positiva de hospitalidade.

Esses aspectos são um desafio enorme a ser enfrentado pelo setor, pois como argumenta Lashley (2015) o conceito de Hospitalidade é algo bastante efêmero, e podem ser comprovado pelo fato de até o final do século $X X$, restaurantes costumarem ser sinônimo de acomodação, o que levava também a apontar cafés, lanchonetes, cantinas, refeições escolares como locais que tinham como objetivo fornecer hospitalidade, e que somente a partir dos anos 1980, a palavra passar a ser utilizada como aglutinadora para descrever todos os estabelecimentos citados e os serviços prestados por eles.

Poulston (2015) oferece uma defini- ção um pouco mais difusa sobre o assunto hospitalidade, argumentando que ela varia de acordo com as características do hotel, a forma como o cliente está se sentindo no momento da acomodação e também aos vários aspectos relativos ao serviço de catering, classificando a hospitalidade como um presente e uma obrigação moral para empresa que se dispõem a oferecer esse tipo de serviço.

Devido as razões apresentadas Luo et al. (2013) argumentam que se faz importante em estratégias que favoreçam o comprometimento do empregado e também aos aspectos que tangem ao relacionamento subordinado liderança, de forma a auxiliar no comportamento positivo dos colaboradores, como o claro objetivo de melhorar a qualidade do serviços prestados na indústria de hospitalidade, por meio principalmente no que se refere ao comportamento dos empregados no que tange ao auxilio e ao suporte aos clientes, aumentando assim a possibilidade de melhorar a percepção do cliente em relação a percepção da hospitalidade e a felicidade dos consumidores durante o consumo de produtos e serviços, tais como: hospedagem, restauração, viagens etc.

Em relação ao comprometimento dos empregados se faz importante convencer as pessoas a respeito da legitimidade da hospitalidade como profissão, pois apesar de ser uma indústria em franco crescimento, muitas pessoas não a veem como uma opção de carreira, é importante se fazer um convencimento dos jovens nesse sentido, para que a indústria possa se desenvolver e dessa forma atrair mais profissionais (Williamson, 2017). 
A explicação do fato das pessoas não acreditarem na legitimidade da hospitalidade como profissão segundo Mooney (2016)se deve ao fato de grande parte dos jovens perceberem essa indústria como algo efêmero devido a associação de trabalho temporário ou por temporada e também aos altos índices de turnover fazendo dessa forma com que os jovens não se sintam atraídos, outro aspecto é o fato de não se sentirem valorizados por seu trabalho.

Uma possível solução para esse aspecto talvez seria a busca por uma conexão entre a faculdade e as empresas de hospitalidade utilizando o fato dos cursos universitários não conseguem oferecer uma visão do mercado e das possibilidades existentes, oferecendo como contrapartida o estado da arte e a capacidade acadêmica que faltam para as empresas (Albano, 2013)

A importância de se fazer as pessoas verem a hospitalidade como uma profissão é o fato de se poder formar uma mão de obra de melhor qualidade e dessa forma, investir na melhoria dos indicadores de qualidade das acomodações por meio da prestação de serviços que principalmente encantem o cliente e que se sintam bem recebidos (Gupta \& Sharma, 2016).

Para que se atinja esse objetivo Awadzi-Calloway, Awadzi \& Awadizi (2016) afirmam que o conhecimento coletivo e as contribuições dos membros da organização servem como um fator direcionador para o sucesso da indústria do turismo e que as empresas devem possuir capacidade de lapidar diamantes brutos, por meio da capacitação e da seleção de colaboradores, objetivando melhorar a sua capacidade e dessa forma se tornarem recursos vitais para a organização como um todo, transformando a indústria do turismo como um todo.

A transformação da indústria do turismo e a organização do trabalho, objetivando a satisfação dos empregados afeta a habilidade deles em serem bons anfitriões e dessa forma criar momentos de hospitalidade na interação deles com os turistas em suas interações diárias (Bethmann, 2017).

Por essa razão os aspectos relacionados à busca do bem-estar do empregado e também do viajante, caracterizam o processo de transferência emocional, que foi teorizado por Hatfield et al. (1994).

Também torna-se importante $o$ investimento no desenvolvimento de uma visão gerencial por parte dos colaboradores, para que eles possam ir além do fato de apenas servir, mas para conseguir anteciparse as situações e dessa forma satisfazer as necessidades dos hospedes, para que isso ocorra se faz necessário que as Universidades invistam no desenvolvimento de uma base curricular que inclua a gestão como uma aspecto primordial, além do fato das empresas também procurarem desenvolver ou contratar cursos de reciclagem para os colaboradores que preencham essa lacuna (Nunkoo, Gursoy, \& Ramkissoon, 2013; Samkange \& Dingani, 2013; Sisson \& Adams, 2013).

Segundo Hemmington \& Gibbons (2017) a importância da desconstrução da hospitalidade e do investimento da capacitação dos colaboradores reside no fato de que a percepção do turista em relação ao bem-estar esta muito ligada a reciprocidade, a generosidade e a capacidade de interação entre os membros das organizações e aos visitantes e por essa razão possui implica- 
ções gerenciais, tornando-se dessa forma um processo de transferência emocional.

Tendo como base o processo de transferência emocional teorizado em Emotional Contagion (Hatfield et al., 1994) e em estudo sobre a hospitalidade (King, 1995), apresenta-se a primeira hipótese de estudo, em que: $\mathbf{H}^{1}$ - haverá uma relação positiva e sig- nificativa entre a busca da felicidade na experiência turística (conjunto de emoções positivas) e o desejo por hospitalidade local (projeção de emoções positivas sobre o local). O quadro 1 a seguir apresenta os estudos que serviram para constituição da hipótese $\mathbf{H}^{\mathbf{1}}$.

Quadro 1 - Principais estudos para constituição teórica da hipótese $\mathbf{H}^{1}$

\begin{tabular}{|l|l|}
\hline \multicolumn{1}{|c|}{ Autores do estudo } & \multicolumn{1}{c|}{ O que analisou } \\
\hline Hemmington \& Gibbons (2017) & Bem-estar e reciprocidade \\
\hline Bojanowska \& Zalewska (2016) & Turismo e felicidade \\
\hline Coffey, Warren, \& Gottfried (2015) & Felicidade e satisfação local \\
\hline $\begin{array}{l}\text { Kaliterna-Lipovčan, Brasjša-Žganec } \\
\text { e Poljanec-Borić (2014) }\end{array}$ & Destino turístico e bem-estar subjetivo \\
\hline Gouveia (2013) & Destino turístico e demandas psicológicas \\
\hline Hatfield et al., (1994) & Bem-estar e transferência emocional \\
\hline
\end{tabular}

Fonte: elaborada pelos autores (2017)

\subsubsection{Congruência entre a autoimagem do turista e a imagem do destino turísti- co}

$\mathrm{Na}$ escolha do destino turístico, levase em conta não apenas os custos de aquisição do serviço, como transporte, alimentação, estadia e outras atividades que podem estar envolvidas, mas também, o julgamento do consumidor sobre a capacidade do destino turístico atender as suas demandas psicológicas (Carvalho, Salazar, \& Neves, 2011; Gouveia, 2013).

No que diz respeito às demandas psicológicas, refere-se à percepção de como o consumidor vê a si próprio, portanto, sua autoimagem, e como ele vê o seu destino turístico, no qual projeta sua autoimagem no momento de escolha (García, Morales, \& Gonzalez, 2007). Por exemplo, indivíduos introspectivos tendem a escolher destinos turísticos mais reservados, considerando também outras atividades que podem ser encontradas no local.

Nawijn(2010) observa ainda que a importância de se estudar esses aspectos se deve ao fato da Indústria de Turismo dar pouca atenção para o humor dos turistas durante as viagens e de como ele afeta a satisfação de vida dos seus clientes como um todo e também como esse aspecto se relaciona ao aumento das receitas dessas empresas.

Porém essa alteração do humor e os índices de felicidade causadas no viajantes são aspectos temporários que devem ser enfatizados sempre, mas que existe em maior grau em pessoas que viajam do que aquelas que não viajam, o que pode ser explicado pelo fato de as memórias positivas remanescentes afetaram positivamente a vida das pessoas (Nawijn, 2011). 
A esse fenômeno é dado o nome de congruência (Hosany \& Martin, 2012) que consiste em uma harmonia entre a autoimagem do consumidor (como ele se vê), e a imagem do destino turístico de sua escolha (Ahn et al., 2013), que por sua vez pode influenciar positivamente a sua avaliação (Kamins \& Gupta, 1994). Aqui, apresenta-se a segunda hipótese de estudo em que: $\mathbf{H}^{2}$ haverá uma relação positiva e significativa entre a busca da felicidade na experiência turística (conjunto de emoções positivas) e a congruência entre a autoimagem do turista (como ele se vê) e a imagem do destino turístico.

Ressaltando que o consumidor pode avaliar mais positivamente destinos turísti- cos que estejam em harmonia com a sua autoimagem (García et al., 2007) e que a percepção de congruência entre autoimagem e destino turístico gera emoções positivas (Choi \& Rifon, 2012), argumenta-se que o fenômeno da congruência irá mediar a relação busca da felicidade na experiência turística e a percepção de hospitalidade do local. Assim, postula-se a terceira hipótese: $\mathbf{H}^{\mathbf{3}}$ - a congruência da autoimagem do consumidor e a imagem de seu destino será uma mediadora da relação busca da felicidade na experiência turística e a percepção de hospitalidade do local turístico. O quadro 2 a seguir apresenta os estudos que serviram para constituição das hipóteses $\mathbf{H}^{2}$ e $\mathbf{H}^{3}$.

Quadro 2- Principais estudos para constituição teórica das hipóteses $\mathbf{H}^{\mathbf{2}}$ e $\mathbf{H}^{\mathbf{3}}$

\begin{tabular}{|l|l|}
\hline \multicolumn{1}{|c|}{ Autores do estudo } & \multicolumn{1}{c|}{ O que analisou } \\
\hline Gouveia (2013) & Destino turístico e demandas psicológicas \\
\hline Ahn et al., (2013) & Imagem do destino turístico \\
\hline Hosany \& Martin (2012) & Congruência \\
\hline Nawijn (2011) & Memórias positivas \\
\hline Carvalho, Salazar, \& Neves (2011) & Destino turístico e demandas psicológicas \\
\hline Zhang \& Bloemer (2008) & Congruência na escolha de marcas \\
\hline García, Morales, \& Gonzalez (2007) & Demandas psicológicas, autoimagem e destino turístico \\
\hline Kamins \& Gupta (1994) & Imagem do destino turístico e avaliação do consumidor \\
\hline
\end{tabular}

Fonte: elaborada pelos autores (2017)

\section{MÉTODO}

A coleta de dados ocorreu por meio de uma survey com a utilização de um instrumento de pesquisa online disponibilizado na rede social FaceBook. 0 instrumento foi composto por 12 afirmativas, sendo que 4 afirmativas mediram a busca da felicidade no destino turístico - <Quando escolho um destino turístico, penso em felicidade; Quando penso em um destino turístico, me sinto feliz; Busco a felicidade quando faço a escolha por um destino turístico; Para mim, escolher um destino turístico é buscar a felicidade $>$ (alfa de cronbach=0,754); 4 afirmativas congruência de autoimagem e imagem do destino <Prefiro destinos turísticos que tenham tudo a ver comigo; Escolho destinos turísticos que reflitam a minha imagem; Escolho destinos turísticos que falem sobre mim; Escolho destinos turísticos que reflitam meu jeito de ser> (alfa de cron- 
bach=0,895); e 4 afirmativas que mediram desejo de hospitalidade local <Quando escoIho meu destino turístico, prefiro aqueles que tenham pessoas acolhedoras; Quando escolho meu destino turístico, prefiro aqueles em que os moradores locais gostem de trocar experiências com os turistas; Quando escolho meu destino turístico, prefiro aqueles em que os moradores locais gostam de interagir com os turistas; Quando escolho meu destino turístico, prefiro aqueles em que os moradores locais sejam hospitaleiros $>$ (alfa de cronbach $=0,823$ ).

\section{RESULTADOS}

A amostra do estudo foi composta por 221 respondentes sendo 166 mulheres e 55 homens. A idade média dos respondentes foi de 33 anos, e fizeram em média 3 viagens turísticas no ano de 2016. Após a checagem dos pressupostos para o uso da técnica de regressão ((Hair, Black, Babin, \&
Anderson, 2010), procedeu-se a análise dos dados.

A busca pela felicidade na experiência turística apresentou relação positiva e significativa com desejo de hospitalidade local $\mathbf{R}^{\mathbf{2}}=0,067 ; F(1,219)=p<0,001$. Da mesma maneira, foi identificada relação positiva e significativa entre busca pela felicidade na experiência turística e congruência da autoimagem do turista e do destino turístico $\mathbf{R}^{\mathbf{2}}=0,240 ; \quad F(1,219)=p<0,001$, e também, efeito de mediação da autoimagem do turista e do destino turístico na relação entre busca da felicidade e desejo de hospitalidade local $\mathbf{R}^{\mathbf{2}}=0,115 ; F(2,218)=p<0,001$. Observou-se que a relação entre a busca da felicidade na experiência turística e o desejo de hospitalidade apresentou $p=>0,05$, portanto, não significante, quando acrescentouse a variável mediadora congruência da autoimagem do turista e desejo hospitalidade local. As Figuras 1 e 2, apresentam os respectivos betas de cada relação.

Figura 1 - Busca da felicidade e hospitalidade

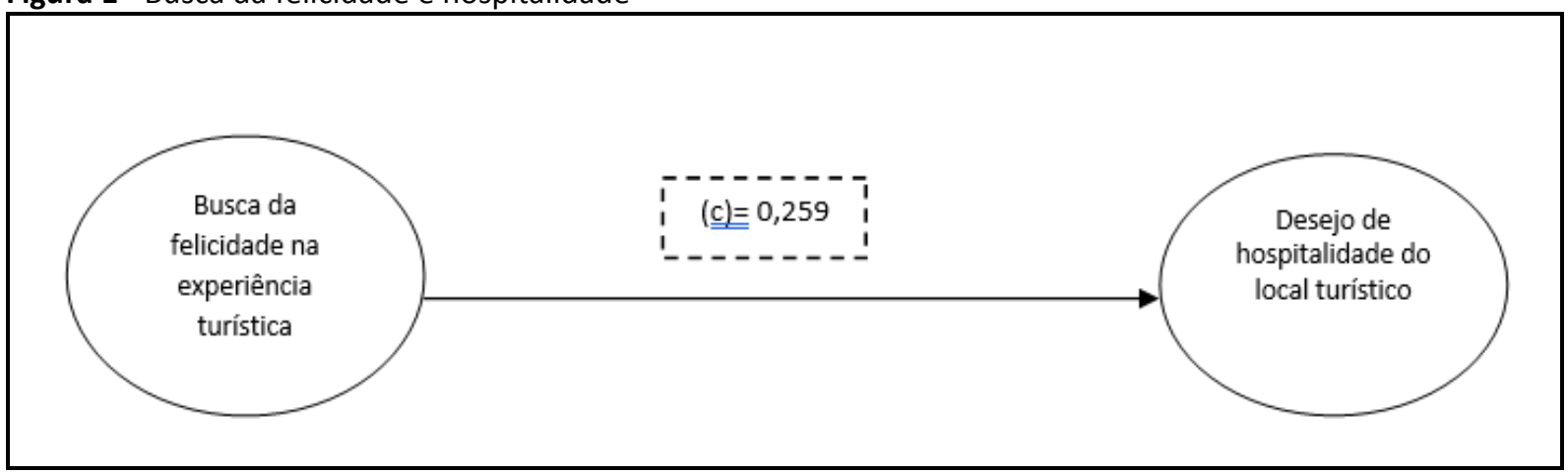

Fonte: Elaborada pelos Autores 
Figura 2 - Mediação da congruência da autoimagem do turista e destino turístico

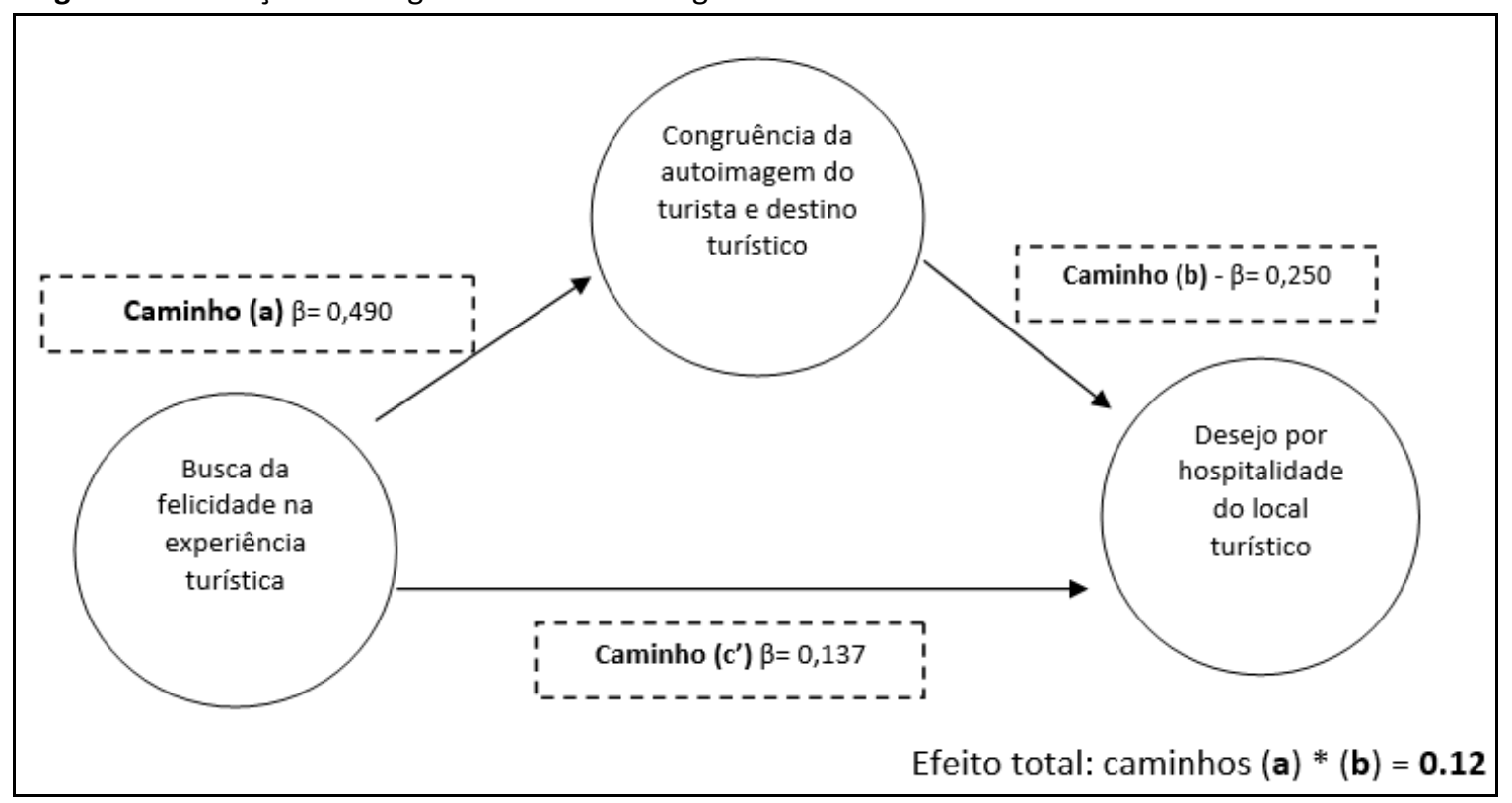

Fonte: Elaborada pelos Autores

Como se pode observar, os referidos valores dos betas indicam a natureza e a força da relação entre cada item do modelo. Todos os betas apresentaram valores positivos, o que indicando relações positivas entre os itens medidos e a força de sua influência sobre os demais itens do modelo, conforme a direção da relação.

\section{DISCUSSÃO GERAL DOS RESULTADOS}

O conceito de felicidade é de natureza subjetiva e dificilmente chegaremos a uma definição única para esse sentimento tão valioso. Por ser um sentimento tão importante para os indivíduos, tornou-se objeto de estudo neste artigo. Assim, buscou-se apresentar a relação entre a busca da felicidade na escolha do destino turístico e analisar a sua relação com a escolha de um destino turístico, cuja característica principal fosse a presença de hospitalidade do local visitado. Vale ressaltar que termo hospitali- dade, neste estudo, foi utilizado no sentido de acolher bem, da possibilidade de interação social e troca de experiência entres o turista e moradores do destino turístico.

Por meio das análises, evidenciou-se que a busca da felicidade por meio do turismo tem relação positiva com o desejo de hospitalidade do destino turístico, ou seja, essa relação indica haver uma projeção emocional do turista sobre o local e àqueles que o recebe. A análise do beta desta relação reforça esse argumento $(\boldsymbol{\beta}=0,259)$, figura 1. Para esse achado, encontramos a explicação teórica já consolidada em Emotional Contagion (Hatfield et al., 1994), na qual o indivíduo quando em estado de emoções positivas tende a projetá-las em outras situações e diferentes contextos.

A importância desse resultado reside no fato do turismo ser muito importante para o crescimento econômico de muitos países, além da capacidade de contribuir com a melhora na saúde geral das pessoas e 
também pelo fato desse aspecto possuir poucos estudos conforme evidenciado por Filep e Bereed-Samuel (2012a) e comprovado ao estudarem uma comunidade de imigrantes etíopes na Austrália, demonstrando o alívio nos níveis de depressão e a melhora da saúde mental desses participantes.

Esse achado também corrobora com a política adotada pelo Butão, na qual baseiam a sua política de Turismo numa estratégia totalmente guiada pela doutrina do Produto Nacional de Felicidade, pois acreditam que o aumento desse índice contribui para o aumento do fluxo de turismo além do fato de promover a boa governança, a promoção da cultura e a felicidade daqueles que visitam e dos que são visitados (Gupta \& Sharma, 2016; Khamrang, 2013; Yang \& Srinivasan, 2016).

Essas ideias são corroboradas pelo estudo de Lipovčan, Brasjša-Žganec e Poljanec-Borić (2014), Gomes, Pinto e Almeida (2017) e Zucco et al. (2017) onde puderam comprovar que a qualidade dos destinos turísticos está muito ligada a percepção de felicidade dos residentes desses locais que estão sendo visitados, demonstrando que quanto maior o a felicidade percebida, maior era a qualidade do destino turístico.

Com destaque maior, a principal contribuição deste estudo foi identificar que a autoimagem do turista (como ele se vê) e a imagem do destino turístico (características e atividades locais), influenciam a percepção de hospitalidade. Algumas evidências destes fenômenos já foram relatadas por (Femenía Millet, 2011; Menezes, 2010).

Esse fenômeno psicológico mostra que um dos fatores mais importantes na escolha do destino turístico reside na rela- ção entre a busca da felicidade e a autoimagem do turista e seu destino (caminho (a) $\boldsymbol{\beta}=$ $0,490)$, figura 2 . Pode-se dizer que a busca da felicidade tem relação com a forma com a qual o turista se vê (autoimagem) e ainda é reforçada pela imagem do destino turístico. Esse fenômeno da harmonia entre ambos pode ser explicado por estudos que abordaram o fenômeno da congruência (Meyers-Levy \& Tybout, 1989; Witt \& Bruce, 1972).

A congruência da autoimagem do turista e seu destino turístico em relação à percepção de hospitalidade do local turístico apresentou (caminho (b) $\boldsymbol{\beta}=0,250$ ). Foi a segunda relação maior forte, indicando congruência de autoimagem e destino são precedentes importantes na percepção de hospitalidade local.

Por fim, observa-se que a relação busca da felicidade e hospitalidade do destino turístico apresentou o menor beta (caminho ( $\left.\left.c^{\prime}\right) \boldsymbol{\beta}=0,137\right)$, quando a mediadora congruência da autoimagem do turista e destino foi acrescentada ao modelo 2 , indicando ser uma mediadora da relação, ou seja, se o turista perceber que o seu destino turístico está alinhado à forma como ele se vê, logo sentirá que os moradores locais são mais hospitaleiros. O efeito total dos caminhos $(\mathbf{a}){ }^{*}(\mathbf{b})=\mathbf{0 . 1 2}$, mostram que o modelo explica $12 \%$ da percepção de hospitalidade do local de destino do turista.

\subsection{Contribuições teóricas, gerenciais e li- mitações}

Do ponto de vista teórico, esse estudo contribui para a compreensão do papel da congruência entre a imagem do turista e 
a imagem de seu destino sobre a percepção de hospitalidade. Logo, amplia a compreensão do processo cognitivo do consumidor na escolha de destino turístico sobre a influência de sentimentos positivos, e o comportamento do consumidor deste tipo de serviço.

Sob a perspectiva substancial, gestores de operadoras de turismo deverão identificar os motivos para a viagem do consumidor, e seu estado emocional quando da apresentação de destinos turísticos e negociação de valores, sobretudo, apresentar alternativas de destinos turísticos que estejam alinhados à forma como o turista se vê (autoimagem).

Algumas limitações estão presentes neste estudo, por exemplo, a utilização do termo felicidade, por ser subjetivo, pode levar a diferentes interpretações por parte dos respondentes da pesquisa. Outra limitação é a utilização de apenas dois fatores explicativos no modelo, logo, pesquisas futuras poderão acrescentar outros fatores para melhorar o poder explicativo do modelo teórico testado neste artigo.

\section{REFERÊNCIAS}

Ahn, T., Ekinci, Y., \& Li, G. (2013). Selfcongruence, functional congruence, and destination choice. Journal of Business Research, 66(6), 719723. https://doi.org/10.1016/j.jbusres.2011.09.009

Albano, D. (2013). Transitioning Hospitality Management into Professional Studies Within a Liberal Arts Perspective. Consortium Journal of Hospitality \& Tourism, 18(2), 1-16.

Alhelalat, J. A. (2015). Consumer Behaviour Analysis of Hospitality Students' Evaluation and Satisfaction with Their Universities. Tourism \& Hospitality Management, 21(2), 127-143.

Awadzi-Calloway, J., Awadzi, C., \& Awadzi, W. (2016). The Role of Human Resource Specialists in
Motivation, Training and Engagement in the Hospitality Industry. Consortium Journal of Hospitality \& Tourism, 20(2), 32-37.

Bareham, J. (2004). Understanding the Hospitality Consumer. International Journal of Hospitality Management, 23(1), 95-97. https://doi.org/10.1016/S0278-4319(03)00068-9

Ben-Ur, J., Mai, E. (Shirley), \& Yang, J. (2015). Hedonic Consumption in Virtual Reality. Journal of Internet Commerce, 14(3), 406-423. https://doi.org/10.1080/15332861.2015.1081792

Bethmann, C. (2017). "Getting milk from the chicken": Hospitality and hospitableness in Bulgaria's mass tourism resorts. Hospitality \& Society, 7(1), 19-41. https://doi.org/10.1386/hosp.7.1.19 1

Bojanowska, A., \& Zalewska, A. (2016). Lay Understanding of Happiness and the Experience of Well-Being: Are Some Conceptions of Happiness More Beneficial than Others? Journal of Happiness Studies, $\quad 17(2)$, 793-815. https://doi.org/10.1007/s10902-015-9620-1

Carvalho, P. D. da C., Salazar, A. M. P. L. V. B. K., \& Neves, J. M. de O. (2011). a Imagem Percebida E O Perfil Do Turista De Um Destino Turístico Cultural: O Caso Do Alto Douro Vinhateiro, Património Da Humanidade. FCHS (DCEC) - Artigos em Atas de Conferências Internacionais, 18.

Chand, M. (2016). Building and Educating Tomorrow's Manpower for Tourism and Hospitality Industry. International Journal of Hospitality \& Tourism Systems, 9(1), 53-57.

Chen, M.-H. (2015). Driving factors of the hospitality industry cycle. Current Issues in Tourism, 18(4), 315-327. https://doi.org/10.1080/13683500.2013.854752

Choi, S. M., \& Rifon, N. J. (2012). It Is a Match: The Impact of Congruence between Celebrity Image and Consumer Ideal Self on Endorsement Effectiveness. Psychology and Marketing, 29(9), 639-650. https://doi.org/10.1002/mar.20550

Coffey, J., Warren, M., \& Gottfried, A. (2015). Does Infant Happiness Forecast Adult Life Satisfaction? Examining Subjective Well-Being in the First Quarter Century of Life. Journal of Happiness Studies, 16(6), 1401-1421. https://doi.org/10.1007/s 10902-014-9556-X 
DeLeire, T., \& Kalil, A. (2010). Does consumption buy happiness? Evidence from the United States. International Review of Economics, 57(2), 163176. https://doi.org/10.1007/s12232-010-0093-6

Espinoza, Francine; Nique, Walter. Experiências emocionais em situações de consumo de produtos: evidências e proposições de pesquisa. In: ENANPAD, 2003. Atibaia (SP). Anais ...Atibaia: ANPAD, 2003.

Femenía Millet, O. (2011). La imagen de un destino turístico como herramienta de marketing. Eumed.Net, 122.

Filep, S., \& Bereded-Samuel, E. (2012a). Holidays against depression? An Ethiopian Australian initiative. Current Issues in Tourism, 15(3), 281-285. https://doi.org/10.1080/13683500.2011.594161

Filep, S., \& Bereded-Samuel, E. (2012b). Holidays against depression? An Ethiopian Australian initiative. Current Issues in Tourism, 15(3), 281-285. https://doi.org/10.1080/13683500.2011.594161

García, R. C. P., Morales, L. M., \& Gonzalez, Y. D. (2007). La imagen del destino y el comportamiento de compra del turista. Teoría y Praxis, 3, 89102.

Gomes, R. D. S. D., Pinto, H. E. dos R. S. da C., \& Almeida, C. M. B. R. de. (2017). Second home tourism in the Algarve - The perception of public managers. Revista Brasileira de Pesquisa Em Turismo, $11(2)$

https://doi.org/10.7784/rbtur.v11i2.1246

197.

Gouveia, D. (2013). Perfil e Motivação dos turistas praticantes de Surf na escolha do destino Algarve. Statewide Agricultural Land Use Baseline 2015, 1. https://doi.org/10.1017/CBO9781107415324.004 Gupta, S. K., \& Sharma, N. (2016). Evaluation of Guest Satisfaction about Hospitality Services: A Case of Accommodation Units in Nainital, Uttarakhand. International Journal of Hospitality \& Tourism Systems, 9(2), 47-55.

Hair, J. F., Black, W. C., Babin, B. J., \& Anderson, R. E. (2010). Multivariate Data Analysis. Vectors. https://doi.org/10.1016/j.ijpharm.2011.02.019

Hatfield, E., Cacioppo, J., \& Rapson, R. (1994). Emotional contagion. Current Directions in Psychological Science. https://doi.org/10.1086/322897
Hemmington, N. (2007). From Service to Experience: Understanding and Defining the Hospitality Business. The Service Industries Journal, 27(6), 747-755.

https://doi.org/10.1080/02642060701453221

Hemmington, N., \& Gibbons, A. (2017). "Pas d'hospitalité': Derrida and the study of hospitality in higher education. Hospitality \& Society, 7(2), $115-131$.

https://doi.org/10.1386/hosp.7.2.115_1

Hemzo, M. A., \& Augusto, J. F. (2010). Gastronomia de Luxo - Entendendo as motivações de consumo. In XXXIV Encontro da Anpad (p. 17).

Hirschman, E. C., \& Holbrook, M. B. (1982). Hedonic Consumption: Emerging Concepts, Methods and Propositions. Journal of Marketing, 46(3), 92. https://doi.org/10.2307/1251707

Hofmann, W., Luhmann, M., Fisher, R. R., Vohs, K. D., \& Baumeister, R. F. (2014). Yes, but are they happy? Effects of trait self-control on affective well-being and life satisfaction. Journal Of Personality, $\quad$ 82(4), 265-277. https://doi.org/10.1111/jopy.12050

Hornsby, G. D., \& Scott-Halsell, S. A. (2015). Minorities in Hospitality Management: The State of Diversity in Hospitality Education. Journal of Hospitality \& Tourism Education, 27(3), 102-111. https://doi.org/10.1080/10963758.2015.1064316

Hosany, S., \& Martin, D. (2012). Self-image congruence in consumer behavior. Journal of Business Research, 65(5), 685-691.

https://doi.org/10.1016/j.jbusres.2011.03.015

Kaliterna-Lipovčan, L., Brajša-Žganec, A., \& Poljanec-Borić, S. (2014). What Is Good for Tourists Should Be Good for Residents Too: The Relationship Between the Quality of the Touristic Offer and Subjective Well-Being of Residents. Tourism Analysis, 19(6), 719-730.

https://doi.org/10.3727/108354214X141468466794 $\underline{48}$

Kamins, M. A., \& Gupta, K. (1994). Congruence between spokesperson and product type: A matchup hypothesis perspective. Psychology \& Marketing, 11(6), 569-586.

https://doi.org/10.1002/mar.4220110605

Kant, I. (2016). Crítica da Razão Prática (1 edition). Martin Claret. 
Khamrang, L. (2013). Modernisation, Globalisation and Development in Bhutan: Tourism as a Catalyst. Journal of Management \& Public Policy, 5(1), 511.

King, C. A. (1995). What is hospitality? International Journal of Hospitality Management, 14(3-4), 219-234. https://doi.org/10.1016/02784319(95)00045-3

Lacher, K. T. (1989). Hedonic Consumption: Music as a Product. Advances in Consumer Research, 16(1), 367-373.

Lashley, C. (2015). Hospitalidade e hospitabilidade. Revista Hospitalidade, 70-92.

Loubser, R., \& Steenekamp, C. (2017). Democracy, well-being, and happiness: A 10-nation study. Journal of Public Affairs, 17(1-2), e1646. https://doi.org/10.1002/pa.1646

Luo, Z., Marnburg, E., Øgaard, T., \& Larsen, S. (2013). Antecedents for Employee Helping Behavior in the Hospitality Industry. Journal of China Tourism Research, 9(4), 395-412. https://doi.org/10.1080/19388160.2013.839411

Lynch, P., Molz, J. G., Mcintosh, A., Lugosi, P., \& Lashley, C. (2011). Theorizing hospitality. Hospitality \& Society.

https://doi.org/10.1386/hosp.1.1.3_2

Meisenberg, G., \& Woodley, M. (2015). Gender Differences in Subjective Well-Being and Their Relationships with Gender Equality. Journal of Happiness Studies, 16(6), 1539-1555.

https://doi.org/10.1007/s10902-014-9577-5

Menezes, P. D. L. de. (2010). Gestão estratégica da imagem: estudo de caso do destino turístico João Pessoa. In SeminTUR Saberes e fazeres no turismo: interfaces (Vol. VI Seminár, p. 13).

Meyers-Levy, J., \& Tybout, A. M. (1989). Schema congruity as a basis for product evaluation. Journal of Consumer Research, 16(1), 39-54. https://doi.org/10.1086/647521

Mooney, S. (2016). Wasted youth in the hospitality industry: Older workers' perceptions and misperceptions about younger workers. Hospitality \& Society, 6(1), 9-30.

https://doi.org/10.1386/hosp.6.1.9_1
Munasinghe, S., Hemmington, N., Schänzel, H., Poulston, J., \& Fernando, T. (2017). Hospitality: Ideologies, characteristics and conditionality in Theravada Buddhism and Western philosophy. Hospitality \& Society, 7(2), 157-180. https://doi.org/10.1386/hosp.7.2.157 1

Nailon, P. (1982). Theory in hospitality management. International Journal of Hospitality Management, 1(3), 135-143.

https://doi.org/10.1016/0278-4319(82)90002-0

Nawijn, J. (2010). The holiday happiness curve: a preliminary investigation into mood during a holiday abroad. International Journal of Tourism Research, 12(3), 281-290.

Nawijn, J. (2011). Happiness Through Vacationing: Just a Temporary Boost or Long-Term Benefits? Journal of Happiness Studies, 12(4), 651-665. https://doi.org/10.1007/s10902-010-9221-y

Nawijn, J., \& Peeters, P. M. (2010). Travelling "green": is tourists' happiness at stake? Current Issues in Tourism, 13(4), 381-392.

https://doi.org/10.1080/13683500903215016

Neeley, C. R., Sam Min, K., \& Kennett- Hensel, P. A. (2010). Contingent consumer decision making in the wine industry: the role of hedonic orientation. Journal of Consumer Marketing, 27(4), 324335.

https://doi.org/10.1108/07363761011052369

Nicolao, L. (2010). Happiness, consumption and hedonic adaptation. Dissertation Abstracts International Section A: Humanities and Social Sciences.

Nunkoo, R., Gursoy, D., \& Ramkissoon, H. (2013). Developments in Hospitality Marketing and Management: Social Network Analysis and Research Themes. Journal of Hospitality Marketing \& Management, 22(3), 269-288.

https://doi.org/10.1080/19368623.2013.753814

Poulston, J. (2015). Expressive labour and the gift of hospitality. Hospitality \& Society, 5(2/3), 145165.https://doi.org/10.1386/hosp.5.2-3.145_1

Rubio Gil, M. A. (1996). Producto turistico: marco conceptual y nuevos patrones de consumo. Estudios sobre consumo, (37), 45-52.

Samkange, F., \& Dingani, S. (2013). Beyond the glass ceiling: a gendered and cultural hospitality management discourse on the advancement of 
women based on integrated research paradigms. Para além do tecto de vidro: um discurso da gestão hoteleira centrado no género e na cultura sobre o avanço das mulheres com base em paradigmas integrados de investigação., 9(1), 20-27.

Sangode, P. B. (2016). A Study of Customer Perception of the Service Quality Parameters of Hotels in Nagpur Region. IUP Journal of Operations Management, 15(3), 38-45.

Sisson, L. G., \& Adams, A. R. (2013). Essential Hospitality Management Competencies: The Importance of Soft Skills. Journal of Hospitality \& Tourism Education, 25(3), 131-145.

https://doi.org/10.1080/10963758.2013.826975

Spruk, R., \& Kešeljević, A. (2016). Institutional Origins of Subjective Well-Being: Estimating the Effects of Economic Freedom on National Happiness. Journal of Happiness Studies, 17(2), 659712. https://doi.org/10.1007/s10902-015-9616-x

Williamson, D. (2017). Too close to servility? Why is hospitality in New Zealand still a "Cinderella" industry? Hospitality \& Society, 7(2), 203-209. https://doi.org/10.1386/hosp.7.2.203 7

Witt, R. E., \& Bruce, G. D. (1972). Group Influence and Brand Choice Congruence. Source Journal of Marketing Research Journal of Marketing Research This content downloaded from, 911110(164), 440-443.

https://doi.org/10.2307/3149312

Yampey, N. (1980). [The concept of happiness]. Acta psiquiátrica y psicológica de América latina, 26(4), 308-17. https://doi.org/10.1007/978-94-0096432-7

Yang, C., \& Srinivasan, P. (2016). Life Satisfaction and the Pursuit of Happiness on Twitter. PLoS ONE, 11(3), 1-30.

https://doi.org/10.1371/journal.pone.0150881

Yap, M. H. T., Ineson, E. M., Tang, C. M. F., \& Fong, L. H. N. (2015). Chinese Hospitality Students' Perceptions of Diversity Management. Journal of Hospitality \& Tourism Education, 27(2), 6068.https://doi.org/10.1080/10963758.2015.1033100

Yap, M. H. T., Jung, T. H., \& Kisseleff, J. (2015). Educators' Perspectives of eLearning in Swiss Private Hospitality Institutions. Journal of Hospitality \& Tourism Education, 27(4), 180-187. https://doi.org/10.1080/10963758.2015.1089509
Zucco, F. D., Quadros, C. M. B. de, Schmitt, J. R., \& Fiuza, T. F. (2017). Imagem e identidade turísticas relacionadas às práticas e bens culturais percebidas pelos residentes: perspectivas a partir da cidade de Blumenau, Santa Catarina, Brasil. Revista Brasileira de Pesquisa em Turismo, 11(2), 320. https://doi.org/10.7784/rbtur.v11i2.1309

Dados dos autores

\section{Leonardo Aureliano-Silva}

Professor do Mestrado Profissional Gestão em Alimentos e Bebidas - Universidade Anhembi Morumbi (UAM) e do curso de graduação em Administração da Escola Superior de Propaganda e Marketing (ESPM), São Paulo, SP, Brasil. E-mail: leonardoaureliano@outlook.com

\section{Paulo Sergio Gonçalves de Oliveira}

Professor do Mestrado Profissional Gestão em Alimentos e Bebidas - Universidade Anhembi Morumbi (UAM), São Paulo, SP, Brasil. E-mail: psoliveira@anhembi.br

\section{Carlos Alberto Alves}

Professor do Mestrado Profissional Gestão em Alimentos e Bebidas e do Programa de PósGraduação em Hospitalidade (Mestrado e Doutorado) - Universidade Anhembi Morumbi (UAM), São Paulo, SP, Brasil. E-mail: calves761@gmail.com 